\title{
Cell structure and cytokinesis alterations in multidrug-resistant Leishmania (Leishmania) amazonensis
}

Received: 24 August 2004/ Accepted: 28 September 2004/Published online: 10 December 2004

(C) Springer-Verlag 2004

\begin{abstract}
Multidrug-resistant Leishmania (Leishmania) amazonensis may be obtained by in vitro selection with vinblastine. In order to determine whether this phenotype is linked to structural alterations, we analyzed the cell architecture by electron microscopy. The vinblastine resistant CL2 clone of $L$. (L.) amazonensis, but not wildtype parasites, showed a cytokinesis dysfunction. The CL2 promastigotes had multiple nuclei, kinetoplasts and flagella, suggesting that vinblastine resistance may be associated with truncated cell division. The subpellicular microtubule plasma membrane connection was also affected. Wild-type parasites treated with vinblastine displayed similar alterations, presenting lobulated and multinucleated cells. Taken together, these data indicate that antimicrotubule drug-selected parasites may show evidence of the mutation of cytoskeleton proteins, impairing normal cell function.
\end{abstract}

\section{Introduction}

Leishmania spp. are parasitic protozoa that cause a wide spectrum of diseases affecting about 12 million individ-

\author{
V. M. Borges · M. A. Vannier-Santos \\ Centro de Pesquisas Gonçalo Moniz, \\ Fundação Oswaldo Cruz, FIOCRUZ, \\ Salvador, BA, Brazil \\ U. G. Lopes · W. De Souza \\ Instituto de Biofísica Carlos Chagas Filho, \\ Universidade Federal do Rio de Janeiro, \\ Rio de Janeiro, RJ, Brazil \\ M. A. Vannier-Santos $(\bowtie)$ \\ Laboratório de Biomorfologia Parasitária \\ e Microscopia Eletrônica, Centro de Pesquisas Gonçalo Moniz, \\ Fundação Oswaldo Cruz (CPqGM-FIOCRUZ), \\ Rua Waldemar Falcão 121, Brotas, 40295-001 \\ Salvador, Bahia, Brazil \\ E-mail: vannier@cpqgm.fiocruz.br \\ Tel.: +55-71-3568784 ext. 236 \\ Fax: + 55-71-356-2155
}

uals with 1.0-1.5 million new cases worldwide per year and at least 350 million people under risk of infection in 88 endemic countries (Desjeux 2004); however, since numerous cases remain asymptomatic for long periods, the incidence of the disease is presumably underestimated.

Chemotherapy still remains the major treatment and control method for most parasitic diseases, particularly because efficient vaccines are not available (Liu and Weller 1996). Nevertheless, drug-resistance mechanisms often reduce infection chemotherapy responsiveness (Sangster et al. 2002). The drugs of choice used for leishmaniasis include the antimonials, which have been in use for more than half a century. Besides important side effects, refractory cases are known to occur (Croft and Yardely 2002). Some degree of drug resistance may be observed in up to $70 \%$ of the cases in different forms of leishmaniasis (Grogl et al. 1991). Miltefosine (or hexadecylphosphocholine) is a rather promising compound recently incorporated into the therapeutic arsenal (Jha et al. 1999; Jacobs 2002), but miltefosine-resistant Leishmania have already been reported (Perez-Victoria et al. 2003a, 2003b). A detailed understanding of the mechanisms underlying drug resistance is required for the development of successful chemotherapy strategies (Cabral 2001; Ponte-Sucre 2003).

The expression of P-glycoprotein efflux pumps, such as the product of the $m d r l$ gene, confers multidrug resistance (MDR) to protozoan cell lines and human tumors (McKeegan et al. 2003). The amplification of genes homologous to the mammalian $m d r$ encoding P-glycoprotein-like molecules has been associated with the development of drug resistance in many Leishmania species (Perez-Victoria et al. 2002; Leandro and Campino 2003).

Tubulin binding agents, such as Vinca alkaloids and taxanes, target essential components of the mitotic and cell organization machinery and are frequently associated with mechanisms of efflux pump-mediated drug resistance (Dumontet 2000; Manetti et al. 2004). Tubulins are the major trypanosomatid proteins, and 
microtubules not only shape the parasites, but also regulate important cell biological events, such as cell morphogenesis and polarity, endocytosis, locomotion, nuclear and mitochondrial/kinetoplast division and cytokinesis (Ploubidou et al. 1999; Gull 2001; Kohl et al. 2003; Dantas et al. 2003). Cell biology approaches may shed light on antiprotozoal chemotherapy (De Souza 2002; Vannier-Santos et al. 2002).

Despite several studies on the molecular and biochemical aspects of MDR in protozoa, the direct effect of the drugs on parasite cell organization is poorly understood. In this study, we used promastigotes of the vinblastine-resistant CL2 clone of the RV100 line of L. (L.) amazonensis presenting a MDR phenotype and exhibiting cross resistance to the chemically unrelated drug adriamycin (Gueiros-Filho et al. 1995). Data presented here indicate that the use of cytoskeletonperturbing compounds may be useful in the elucidation of Leishmania cell biology.

\section{Materials and methods}

\section{Chemicals}

Vinblastine (Velbam) was purchased from Eli Lilly do Brasil (São Paulo, SP, Brazil). Fetal calf serum, glutaraldehyde and osmium tetroxide were obtained from Sigma (St. Louis, Mo.). Reagents used in the culture medium were purchased from Difco Laboratories (Detroit, Mich.).

Parasite maintenance and growth conditions

Promastigotes of L. (L.) amazonensis (IFLA/BR/67/ PH8) were kindly provided by Dr. G. Grimaldi (Instituto Oswaldo Cruz, FIOCRUZ, Brazil) and maintained in brain and heart infusion (BHI) liquid medium supplemented with $10 \%$ fetal calf serum at $25^{\circ} \mathrm{C}$ (VannierSantos et al. 1995). The cells were subcultured weekly.

\section{Selection of Leishmania drug-resistant cell lines}

L. (L.) amazonensis promastigotes were selected by gradually increasing the vinblastine concentration as described previously (Coderre et al. 1983; Gueiros-Filho et al. 1995). Briefly, promastigotes were grown for 2 weeks in medium supplemented with $10 \mu \mathrm{M}$ vinblastine. Then the cells were transferred to medium containing $20 \mu \mathrm{M}$ vinblastine and allowed to grow for another 2-week period and so on until the promastigotes were able to grow in $100 \mu \mathrm{M}$ vinblastine (RV100 line). We studied the CL2 clone of line RV100. Continuous drug pressure was maintained during all experiments. For short-term treatment, promastigotes were treated with $10 \mu \mathrm{M}$ vinblastine for $1-72 \mathrm{~h}$.
Electron microscopy

The promastigotes of $L$. (L.) amazonensis were rinsed in PBS, $\mathrm{pH} 7.4$, fixed in $2.5 \%$ glutaraldehyde and $0.2 \%$ picric acid in $0.1 \mathrm{M}$ cacodylate buffer, $\mathrm{pH} 7.4$ for $60 \mathrm{~min}$. They were then rinsed and postfixed in $1 \%$ $\mathrm{OsO}_{4}, 0.8 \% \mathrm{~K}_{3} \mathrm{Fe}(\mathrm{CN})_{6}$ and $5 \mathrm{mM} \mathrm{CaCl}_{2}$ in the same buffer, for $1 \mathrm{~h}$. For transmission electron microscopy (TEM), the samples were dehydrated in acetone and embedded in epoxy Polybed resin (Polyscience). Ultrathin sections were stained with uranyl acetate, lead citrate and were observed in a Zeiss 900 or Zeiss 109 electron microscope.

For scanning electron microscopy (SEM), fixed cells were adhered to coverslips covered with poly-L-lysine and post-fixed with osmium tetroxide as above. The specimens were then dehydrated in ethanol and critical point dried in a Balzers apparatus, mounted on metal stubs, covered with an approximately $20 \mathrm{~nm}$-thick gold layer and observed in a Zeiss 940 digital scanning electron microscope.

\section{Results}

We compared the structural organization of the wildtype before and after vinblastine treatment and $\mathrm{MDR}^{+}$ vinblastine-resistant $L$. (L.) amazonensis promastigotes by TEM and SEM.

Surface topography assessed by SEM showed that, contrary to wild-type parasites (Fig. 1a), the vinblastineresistant promastigotes were abnormally shaped, presented short, twisted or absent flagella (Fig. 1b) and displayed numerous membrane invaginations (Fig. 2a, b) and occasionally multiple flagella (Fig. 2c), presumably indicating truncated or deregulated cytokinesis.

Ultrathin sections of the CL2 parasites revealed altered membrane-microtubule connections and microtubule-devoid membrane protrusions (Fig. 3a-c). The membrane-microtubule connecting filaments and the distance between them were irregular (Fig. 3a). It is noteworthy that endoplasmic reticulum (ER) cisternae were associated with, and even entered such extensions (Fig. 3b, c).

Promastigotes often presented surface invaginations forming long clefts associated with subpellicular microtubules and ER cisternae (Fig. 3d) which occasionally conferred the parasites a multilobulated appearance (Fig. 3e). We found CL2 parasites with remarkably enlarged kinetoplasts with several randomly distributed kDNA bars (Fig. 3f) and multinucleate cells (polykarions) were also seen, presenting nuclei with a normal ultrastructural appearance (Fig. 3g). Mitochondrial distribution also appeared atypical (not shown).

In order to determine whether these alterations could directly result from the Vinca alkaloid, we incubated wild-type parasites with vinblastine for different periods. Promastigotes cultured with $10 \mu \mathrm{M}$ vinblastine for $72 \mathrm{~h}$ 

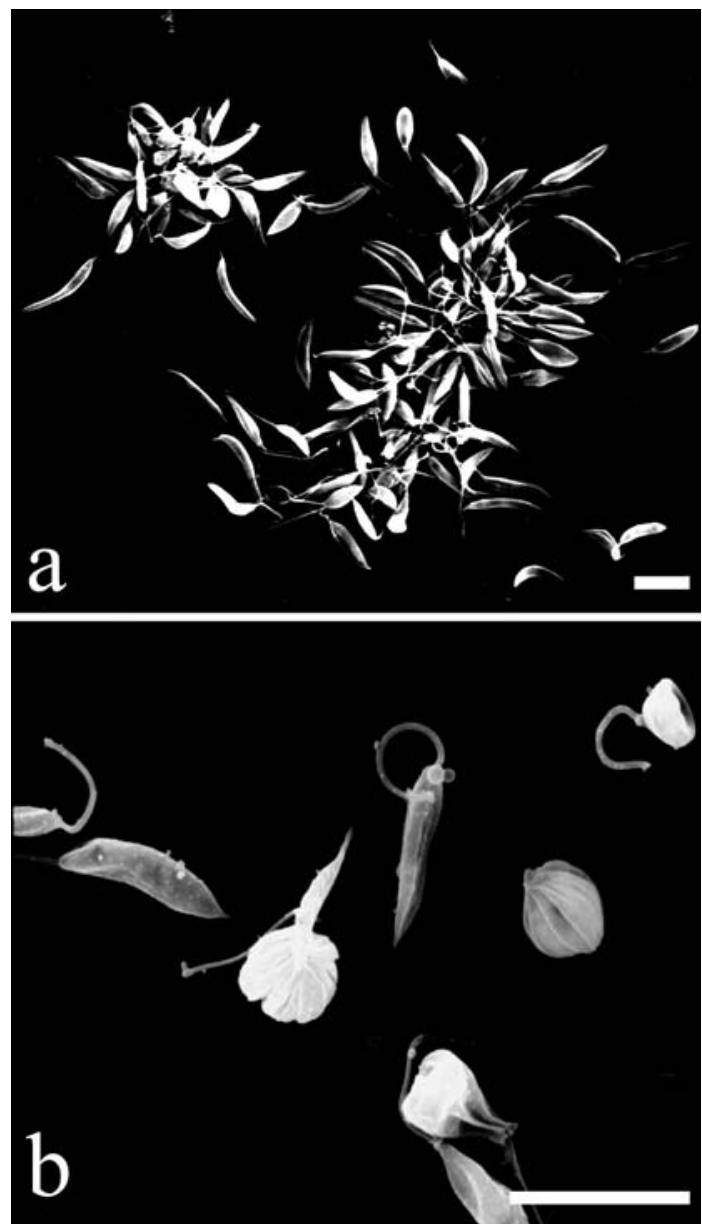

Fig. 1 a Scanning electron micrograph of control wild-type Leishmania (L.) amazonensis displaying the normal morphology of promastigotes. b SEM of CL2 vinblastine-resistant parasites showing irregularly shaped and often rounded forms with short, twisted and sometimes absent flagella. Bars represent $10 \mu \mathrm{m}$

presented multilobulated and multinucleated cells (Fig. 4), strongly indicating impaired cytokinesis.

\section{Discussion}

Antimicrotubule agents are useful tools in leishmaniasis chemotherapy studies both because they may be leishmanicidal (Chan and Fong 1990; Chan et al. 1995; Bhattacharya et al. 2002, 2004; Werbevetz 2002) and for their ability to select parasites with multidrug-resistant $\left(\mathrm{MDR}^{+}\right.$) phenotypes (Gueiros-Filho et al. 1995).

Vinblastine-resistant parasites displayed abnormal shapes and loss of cell polarity, indicating an altered cytoskeletal function. Flagellar alterations suggest that the axoneme microtubules were affected in these cells. Deformed and twisted flagella were also reported in Leishmania (L.) donovani exposed to antimicrotubule agents (Havens et al. 2000).

Since the subpelicullar microtubule membrane is rather stable in trypanosomatid parasites (De Souza
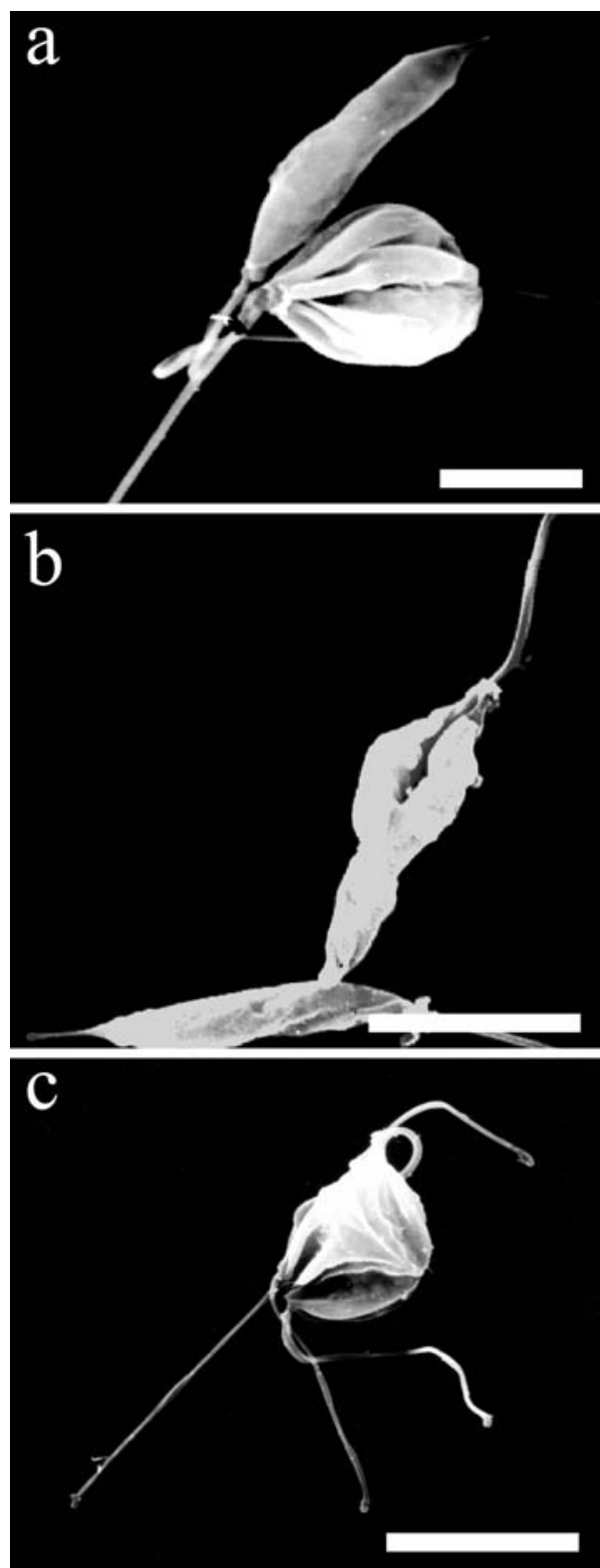

Fig. 2 a Many cells presented long, single or multiple surface invaginations which seemed to be formed from the anterior end (b). c Some parasites presented numerous flagella, indicating truncated cell division. Bars represent either $5 \mu \mathrm{m}(\mathbf{a}, \mathbf{b})$ or $10 \mu \mathrm{m}(\mathbf{c})$

1989), such microtubule-free protrusions as those observed in $\mathrm{MDR}^{+}$Leishmania are only found under particular conditions such as ligand-induced shedding (Saraiva et al. 1989; Vannier-Santos et al. 1992) and protein kinase C activation (Vannier-Santos et al. 1988). Protein kinase $\mathrm{C}$ is able to regulate $\mathrm{P}$-glycoprotein activity (Fine et al. 1996).

Although the ER approaches the parasite plasma membrane (Pimenta and De Souza 1985), the biological role of this phenomenon remains to be elucidated. It was recently shown that P-glycoprotein is transported from the ER to the Golgi complex and then to the cell surface (Fu et al. 2004). Blockage of ER-Golgi trafficking by brefeldin $\mathrm{A}$ and monensin resulted in daunorubicin 
Fig. 3 a-c CL2 clone cells often presented cytoplasm and microtubule-free membrane projections. a Microfilament connections between subpellicular microtubules and the plasma membrane were usually observed, as in controls (arrow), but irregular amorphous material was also associated with microtubules in drug-resistant parasites (arrowhead). b, c Endoplasmic reticulum cisternae were seen in association with and even entering such protrusions (arrow in c). d The surface invaginations were scaffolded by subpellicular microtubules, e and gave the parasites a lobulated appearance. f CL2 parasites showed an impaired kinetoplast, but not nuclear division (g). Observe the kinetoplast presenting multiple k-DNA bars $(K)$, but the nuclei $(N)$, sometimes multiple, kept a normal ultrastructure (g). Bars represent either $0.1(\mathbf{a}-\mathbf{c})$ or $0.5 \mu \mathrm{m}(\mathbf{d}-\mathbf{g})$
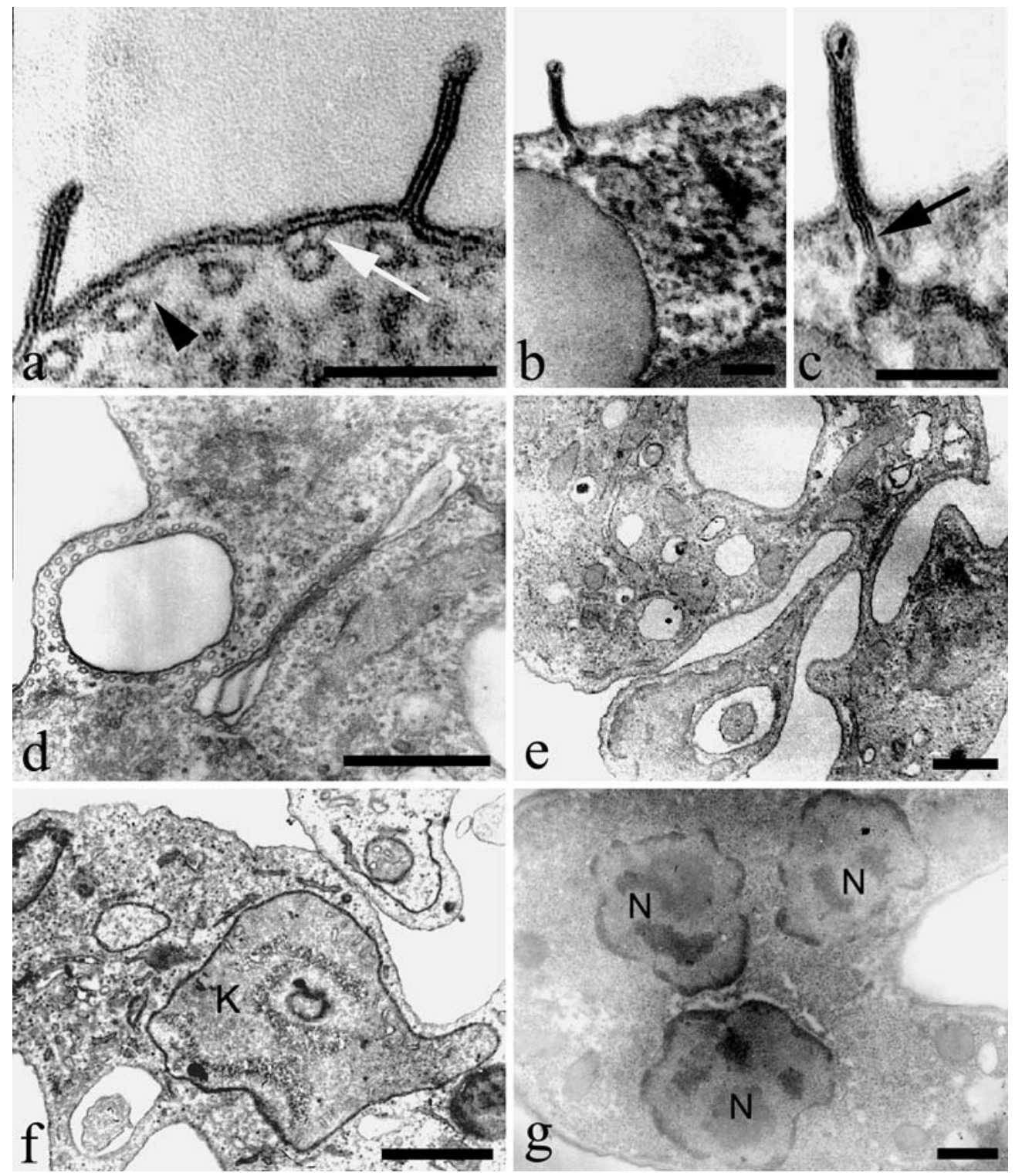

accumulation in HeLa cells. Nevertheless, the role of ER cisternae-membrane protrusions in the Leishmania $\mathrm{MDR}^{+}$phenotype is yet to be determined.

The multiple membrane infolds observed in CL2 parasites are interpreted as slowed or interrupted division furrows, which are observed particularly at the anterior end of cells where cell division begins in trypanosomatids (Molyneaux and Killick-Kendrick 1987). Cell surface microvilli form a diffusion barrier which may take part in MDR (Lange and Gartzke 2001), but it is not known whether the CL2 parasites numerous surface infolds, observed by electron microscopy, take part in drug resistance.

Multiflagellate and multinucleate cells appeared as a result of truncated cell division. Similarly, Vinca alkaloids produced a reversible blockage of cytokinesis in $T$. cruzi with the presence of multiple nuclei and kinetoplasts (Grellier et al. 1999). Other tubulin inhibitors impaired cytokinesis, producing aberrant cell types

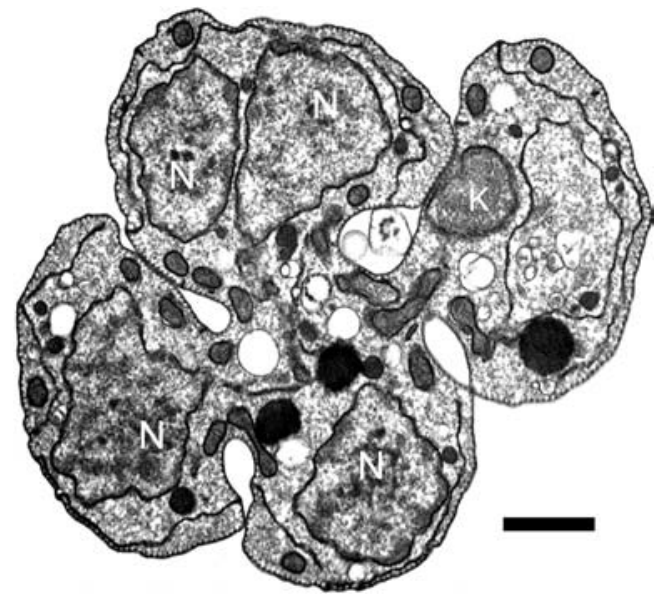

Fig. 4 A wild-type $L$. (L.) amazonensis promastigote treated with $10 \mu \mathrm{M}$ vinblastine for $72 \mathrm{~h}$. Four lobules, four nuclei $(N)$ and one kinetoplast $(K)$ can be seen, indicating impairment of cytokinesis. Bar represents $1 \mu \mathrm{m}$ 
including enucleated parasites or zoids in $L$. (L.) donovani (Havens et al. 2000) and T. cruzi (Grellier et al. 1999), as well as blockage of the promastigote cell cycle (Moulay et al. 1996). The interference with kinetoplast division in $\mathrm{MDR}^{+}$Leishmania may be explained by a microtubule-mediated mechanism of kDNA and kinetoplast repositioning as reported in $L$. (L.) donovani (Havens et al. 2000) and Trypanosoma brucei (Matthews et al. 1995), which may comprise a cell cycle checkpoint controlling cytokinesis (Ploubidou et al. 1999). Interestingly, nuclear division was not affected under the conditions employed here, suggesting the involvement of distinct tubulin isoforms or hampered access to the intranuclear spindle. Here, the cell vinblastine alterations are similar to those observed in the vinblastineresistant $L$. (L.) amazonensis cell line.

Since the survival of drug-induced polykarions may be associated with an altered susceptibility to different compounds (Court et al. 1993), these aberrant forms must be considered in MDR studies. Although the early vinblastine effects on Leishmania may be reversed, the MDR phenotype and the ultrastructural alterations produced by long-term treatment were stable. This indicates that prolonged drug exposure may lead to the selection of populations bearing cytoskeleton protein mutations.

In this regard, different cell lines resistant to microtubule-targeting agents such as the Vinca alkaloids, colchicine, colcemid, griseofulvin and taxanes such as taxol, may rely on the rise of mutants displaying distinct $\beta$-tubulin isoforms with different biochemical properties. Drug resistance may be pgp expression-independent and not associated with the $\mathrm{MDR}^{+}$phenotype (Cabral et al. 1980; Jaffrezou et al. 1995; Kavallaris et al. 1997; Cabral 2001; Werbovetz 2002; Ponte-Sucre 2003). Similarly, drug resistance in $T$. cruzi infections may be unrelated to pgp gene expression (Murta et al. 2001), and multigene drug-resistance mechanisms have been reported in vinblastine-resistant Leishmania species (Henderson et al. 1992; Chow et al. 1993; Wong et al. 1994). Antimonial resistance in visceral leishmaniasis may rely on altered protein phosphorylation (Singh et al. 2003).

The alterations observed in resistant parasites may be epiphenomena rather than related to efflux pump activity (Ponte-Sucre 2003) or linked to the dysfunction of cellular volume control. In this regard, P-glycoprotein is a regulator of volume sensing (Okada 1997) and cell swelling may inhibit its activity (Sardini et al. 1994). Interestingly, P-glycoproteins play a role in phospholipid transport (Tannert et al. 2003). However, RV-100 promastigotes are sensitive to the pgp inhibitor verapamil, which leads to the accumulation of pgp substrates in the cells (Gueiros-Filho et al. 1995), indicating that although there are critical morphological alterations, cell survival is related to the MDR phenotype and overexpression of the MDR gene in RV100.

It is well known that microtubule function may influence actin filament architecture and the $T$. brucei subpellicular microtubules may be stabilized by low molecular weight cytoskeleton-associated proteins (Vedrenne et al.
2002). The $\mathrm{MDR}^{+}$phenotype is associated with actin microfilament organization and microfilament disruption causes loss of this phenotype (Tsuruo and Iida 1986; Takeshita et al. 1998). Interestingly, the actin network is only partially restored after colchicine removal (Erokhina et al. 1994). Furthermore, P-glycoprotein may be connected to actin through ezrin/radixin/moesin proteins (Luciani et al. 2002). Therefore, growth with vinblastine may lead to the selection of actin or microtubule-associated protein mutants. Thus, the effects of antimicrotubule agents in $T$. cruzi may be mediated by an altered interaction between microtubules and associated proteins (Grellier et al. 1999). In addition, a novel actin isotype has recently been observed associated with the Leishmania subpellicular microtubules (Sahasrabubbhe et al. 2004). It is noteworthy that the membrane-microtubule connection in the parasites was remarkably altered. Our data indicate that drug-induced selection of resistance may lead to an accumulation of mutants with anomalous cell functioning and the use of cytoskeleton-perturbing compounds may shed light on Leishmania cell and organelle architecture and division.

Acknowledgements We are grateful to Mr. Claudio P. Figueira for technical assistance. This project was supported by the Conselho Nacional de Desenvolvimento Científico e Tecnológico (CNPq), Coordenação de Aperfeiçoamento de Pessoal do Ensino Superior (CAPES), Fundação Carlos Chagas Filho de Amparo à Pesquisa do Estado do Rio de Janeiro (FAPERJ), Programa de Núcleos de Excelência (PRONEX/MCT), Fundação Oswaldo Cruz, FIOCRUZ and Fundação de Amparo à Pesquisa do Estado da Bahia (FAPESB). All the experiments performed here comply with Brazilian law and FIOCRUZ - Ministry of Health guidelines.

\section{References}

Bhattacharya G, Salem MM, Werbovetz KA (2002) Antileishmanial dinitroaniline sulfonamides with activity against parasite tubulin. Bioorg Med Chem Lett 12:2395-2398

Bhattacharya G, Herman J, Delfin D et al (2004) Synthesis and antitubulin activity of $\mathrm{N}(1)$ - and $\mathrm{N}(4)$-substituted 3,5-dinitro sulfanilamides against African trypanosomes and Leishmania. J Med Chem 47:1823-1832

Cabral F (2001) Factors determining cellular mechanisms of resistance to antimitotic drugs. Drug Resist Updat 4:3-8

Cabral F, Sobel ME, Gottesman MM (1980) CHO mutants resistant to colchicine, colcemid or griseofulvin have an altered betatubulin. Cell 20:29-36

Chan MM, Fong D (1990) Inhibition of leishmanias but not host macrophages by the antitubulin herbicide trifluralin. Science 249:924-926

Chan MM, Grogl M, Callahan H, Fong D (1995) Efficacy of the herbicide trifluralin against four P-glycoprotein-expressing strains of Leishmania. Antimicrob Agents Chemother 39:16091611

Chow LM, Wong AK, Ullman B, Wirth DF (1993) Cloning and functional analysis of an extrachromosomally amplified multidrug resistance-like gene in Leishmania enriettii. Mol Biochem Parasitol 60:195-208

Coderre JA, Beverley SM, Schimke RT, Santi DV (1983) Overproduction of a bifunctional thymidylate synthetase-dihydrofolate reductase and DNA amplification in methotrexateresistant Leishmania tropica. Proc Natl Acad Sci U S A 80:2132-2136 
Court JB, Burn C, Louis DS, Moore JL (1993) The survival of cytochalasin-induced polykaryons following exposure to cytotoxic agents. Cell Biol Int 17:291-303

Croft SL, Yardley V (2002) Chemotherapy of leishmaniasis. Curr Pharm Des 8:319-342

Dantas AP, Barbosa HS, De Castro SL (2003) Biological and ultrastructural effects of the anti-microtubule agent taxol against Trypanosoma cruzi. J Submicrosc Cytol Pathol 35:287-294

De Souza W (1989) Components of the cell surface of trypanosomatids. Prog Protistol 3:87-184

De Souza W (2002) Special organelles of some pathogenic protozoa. Parasitol Res 88:1013-1025

Desjeux C (2000) Leishmaniasis: current situation and new perspectives. Comp Immunol Microbiol Infect Dis 27:305-318

Dumontet C (2000) Mechanisms of action and resistance to tubulin-binding agents. Expert Opin Investig Drugs 9:779-788

Erokhina MV, Shtil AA, Shushanov SS, Sidorova TA, Stavrovskaya AA (1994) Partial restoration of the actin cytoskeleton in transformed Syrian hamster fibroblasts selected for low levels of 'typical' multidrug resistance. FEBS Lett 341:295-298

Fine RL, Chambers TC, Sachs CW (1996) P-glycoprotein, multidrug resistance and protein kinase C. Oncologist 1:261-268

Fu D, Bebawy M, Kable EP, Roufogalis BD (2004) Dynamic and intracellular trafficking of P-glycoprotein-EGFP fusion protein: implications in multidrug resistance in cancer. Int $\mathrm{J}$ Cancer 109:174-181

Grellier P, Sinou V, Garreau-de Loubresse N, Bylen E, Boulard Y, Schrevel J (1999) Selective and reversible effects of vinca alkaloids on Trypanosoma cruzi epimastigote forms: blockage of cytokinesis without inhibition of the organelle duplication. Cell Motil Cytoskeleton 42:36-47

Grogl M, Martin RK, Oduola AM, Milhous WK, Kyle DE (1991) Characteristics of multidrug resistance in Plasmodium and Leishmania: detection of P-glycoprotein-like components. Am J Trop Med Hyg 45:98-111

Gueiros-Filho FJ, Viola JP, Gomes FC et al (1995) Leishmania amazonensis: multidrug resistance in vinblastine-resistant promastigotes is associated with rhodamine 123 efflux, DNA amplification, and RNA overexpression of a Leishmania mdr1 gene. Exp Parasitol 81:480-490

Gull K (2001) Protist tubulins: new arrivals, evolutionary relationships and insights to cytoskeletal function. Curr Opin Microbiol 4:427-432

Havens CG, Bryant N, Asher L et al (2000) Cellular effects of leishmanial tubulin inhibitors on $L$. donovani. Mol Biochem Parasitol 110:223-236

Henderson DM, Sifri CD, Rodgers M, Wirth DF, Hendrickson N, Ullman B (1992) Multidrug resistance in Leishmania donovani is conferred by amplification of a gene homologous to the mammalian mdr1 gene. Mol Cell Biol 12:2855-2865

Jacobs S (2002) An oral drug for leishmaniasis. N Engl J Med 347:1737-1738

Jaffrezou JP, Dumontet C, Derry WB et al (1995) Novel mechanism of resistance to paclitaxel (Taxol) in human K562 leukemia cells by combined selection with PSC 833. Oncol Res 7:517-527

Jha TK, Sundar S, Thakur CP et al (1999) Miltefosine, an oral agent, for the treatment of Indian visceral leishmaniasis. N Engl J Med 341:1795-1800

Kavallaris M, Kuo DY, Burkhart CA et al (1997) Taxol-resistant epithelial ovarian tumors are associated with altered expression of specific beta-tubulin isotypes. J Clin Invest 100:1282-1293

Kohl L, Robinson D, Bastin P (2003) Novel roles for the flagellum in cell morphogenesis and cytokinesis of trypanosomes. EMBO J 22:5336-5346

Lange K, Gartzke J (2001) Microvillar cell surface as a natural defense system against xenobiotics: a new interpretation of multidrug resistance. Am J Physiol Cell Physiol 281:C369-C385

Leandro C, Campino L (2003) Leishmaniasis: efflux pumps and chemoresistance. Int J Antimicrob Agents 22:352-357

Liu LX, Weller PF (1996) Antiparasitic drugs. N Engl J Med $334: 1178-1184$
Luciani F, Molinari A, Lozupone F et al (2002) P-glycoprotein-actin association through ERM family proteins: a role in P-glycoprotein function in human cells of lymphoid origin. Blood 99:641648

Manetti F, Maccari L, Corelli F, Botta M (2004) 3-D QSAR models of interactions between beta-tubulin and microtubule stabilizing antimitotic agents (MSAA): a survey on taxanes and epothilones. Curr Top Med Chem 4:203-217

Matthews KR, Sherwin T, Gull K (1995) Mitochondrial genome repositioning during the differentiation of the African trypanosome between life cycle forms is microtubule mediated. J Cell Sci 108:2231-2239

McKeegan KS, Borges-Walmsley MI, Walmsley AR (2003) The structure and function of drug pumps: an update. Trends Microbiol 11:21-297

Molyneux DH, Killick-Kendrick R (1987) Morphology, ultrastructure and life cycles. In: Peters W, Killick-Kendrick R (eds) The leishmaniases in biology and edicine. Academic Press, New York, pp 121-176

Moulay L, Robert-Gero M, Brown S, Gendron MC, Tournier F (1996) Sinefungin and taxol effects on cell cycle and cytoskeleton of Leishmania donovani promastigotes. Exp Cell Res 226:283-291

Murta SM, Dos Santos WG, Anacleto C, Nirde P, Moreira ES, Romanha AJ (2001) Drug resistance in Trypanosoma cruzi is not associated with amplification or overexpression of P-glycoprotein (PGP) genes. Mol Biochem Parasitol 117:223-228

Okada Y (1997) Volume expansion-sensing outward-rectifier Cl-channel: fresh start to the molecular identity and volume sensor. Am J Physiol 273:C755-C789

Perez-Victoria JM, Di Pietro A, Barron D, Ravelo AG, Castanys S, Gamarro F (2002) Multidrug resistance phenotype mediated by the P-glycoprotein-like transporter in Leishmania: a search for reversal agents. Curr Drug Targets 3:311-333

Perez-Victoria FJ, Castanys S, Gamarro F (2003a) Leishmania donovani resistance to miltefosine involves a defective inward translocation of the drug. Antimicrob Agents Chemother 47:2397-2403

Perez-Victoria FJ, Gamarro F, Ouellette M, Castanys S (2003b) Functional cloning of the miltefosine transporter. A novel P-type phospholipid translocase from Leishmania involved in drug resistance. J Biol Chem 278:49965-49971

Pimenta PF, De Souza W (1985) Fine structure and cytochemistry of the endoplasmic reticulum and its association with the plasma membrane of Leishmania mexicana amazonensis. J Submicrosc Cytol 17:413-419

Ploubidou A, Robinson DR, Docherty RC, Ogbadoyi EO, Gull K (1999) Evidence for novel cell cycle checkpoints in trypanosomes: kinetoplast segregation and cytokinesis in the absence of mitosis. J Cell Sci 112:4641-4650

Ponte-Sucre A (2003) Physiological consequences of drug resistance in Leishmania and their relevance for chemotherapy. Kinetoplastid Biol Dis 2:14

Sahasrabuddhe AA, Bajpai VK, Gupta CM (2004) A novel form of actin in Leishmania: molecular characterization, subcellular localization and association with subpellicular microtubules. Mol Biochem Parasitol 134:105-114

Sangster N, Batterham P, Chapman HD et al (2002) Resistance to antiparasitic drugs: the role of molecular diagnosis. Int J Parasitol 32:637-653

Saraiva EM, Vannier-Santos MA, Silva-Filho FC, De Souza W (1989) Anionic site behavior in Leishmania and its role in the parasite-macrophage interaction. J Cell Sci 93:481-489

Sardini A, Mintenig GM, Valverde MA et al (1994) Drug efflux mediated by the human multidrug resistance P-glycoprotein is inhibited by cell swelling. J Cell Sci 107:3281-3290

Singh N, Singh RT, Sundar S (2003) Novel mechanism of drug resistance in kala azar field isolates. J Infect Dis 188:600-607

Takeshita H, Kusuzaki K, Ashihara T, Gebhardt MC, Mankin HJ, Hirasawa Y (1998) Actin organization associated with the expression of multidrug resistant phenotype in osteosarcoma cells and the effect of actin depolymerization on drug resistance. Cancer Lett 126:75-81 
Tannert A, Pohl A, Pomorski T, Herrmann A (2003) Proteinmediated transbilayer movement of lipids in eukaryotes and prokaryotes: the relevance of $\mathrm{ABC}$ transporters. Int $\mathbf{J}$ Antimicrob Agents 22:177-187

Tsuruo T, Iida H (1986) Effects of cytochalasins and colchicine on the accumulation and retention of daunomycin and vincristine in drug resistant tumor cells. Biochem Pharmacol 35:10871090

Vannier-Santos MA, Pimenta PF, De Souza W (1988) Effects of phorbol ester on Leishmania mexicana amazonensis: an ultrastructural and cytochemical study. J Submicrosc Cytol Pathol 20:583-593

Vannier-Santos MA, Saraiva EM, Martiny A, Neves A, De Souza W (1992) Fibronectin shedding by Leishmania may influence the parasite-macrophage interaction. Eur J Cell Biol 59:389-397
Vannier-Santos MA, Urbina JA, Martiny A, Neves A, De Souza W (1995) Alterations induced by the antifungal compounds ketoconazole and terbinafine in Leishmania. J Eukaryot Microbiol 42:337-346

Vannier-Santos MA, Martiny A, Se Souza W (2002) Cell biology of Leishmania spp.: invading and evading. Curr Pharm Des 8:297318

Vedrenne C, Giroud C, Robinson DR et al. (2002) Two related subpellicular cytoskeleton-associated proteins in Trypanosoma brucei stabilize microtubules. Mol Biol Cell 13:1058-1070

Werbovetz KA (2002) Tubulin as an antiprotozoal drug target. Mini Rev Med Chem 2:519-529

Wong AK, Chow LM, Wirth DF (1994) A homologous recombination strategy to analyze the vinblastine resistance property of the V-circle in Leishmania. Mol Biochem Parasitol 64:75-86 